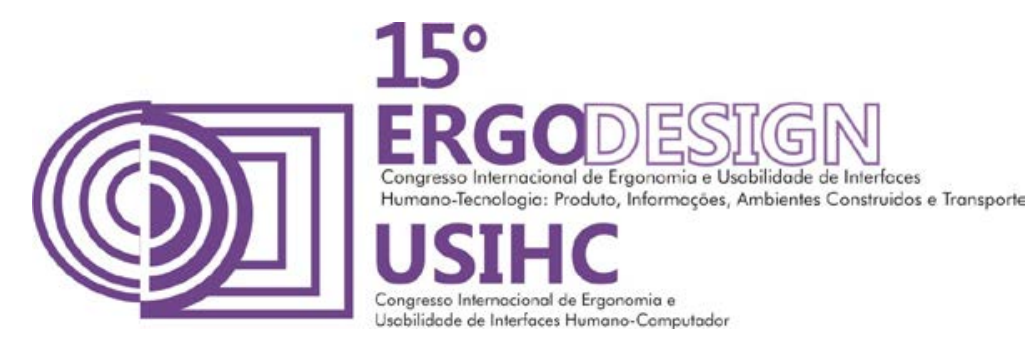

\title{
AVALIAÇÃO EM SMARTPHONES: PORQUE USUÁRIOS PREFEREM OU NÃO APLICATIVOS NATIVOS DE CÂMERA?
}

\section{EVALUATION IN SMARTPHONES: WHY USERS PREFER OR PREFER NOT TO USE NATIVE CAMERA APPLICATIONS?}

\author{
ZANY, Agnes Karoline da Silva (1); \\ MACIEL, Francimar Rodrigues (2); \\ (1) Graduanda em Psicologia - Faculdade Martha Falcão \\ e-mail:karol.zany@gmail.com \\ (2) Mestranda em Ergonomia - Universidade Federal de Pernambuco \\ e-mail:narf2916@gmail.com
}

\begin{abstract}
RESUMO
O presente artigo tem por objetivo apresentar o relato de um estudo onde buscou-se compreender a preferência pelos serviços nativos da câmera em smartphones. A partir de observações e entrevistas chegou-se a resultados que sugerem que usuários de smartphones tendem a preferir recursos não nativos devido à limitações e ausência de funções de personalização. Através da análise de conteúdo proposta por Bardin (2011) foi possível entender que a funcionalidade que o usuário espera de um aplicativo de câmera digital vai além da simples tarefa de registrar uma cena, sendo necessário recursos extras para a devida satisfação do cliente.
\end{abstract}

Palavras-chaves: câmera, fotografia, smartphone, avaliação

\section{ABSTRACT}

Abstract: This article report the findings of a study aimed at understanding users preferences for native vs. non-native digital camera applications on smartphones. The results of observations and interviews suggest that smartphone users tend to prefer non-native application. Using content analysis as proposed by Bardin(2011) it was possible to understand that the expectation users have for applications of this kind goes beyond the simple task of registering a scene.

Keywords: camera, photo, smartphone, evaluation

\section{INTRODUÇÃO}

A fotografia surgiu, no século XIX, a partir de uma necessidade de registrar e documentar várias situações. "No ano de 1826, um francês chamado Joseph Nicéphore Niépce, fazendo testes com um material coberto com betume da Judéia e sais de prata, consegue gravar e fixar uma imagem (CALAÇA, 2012). Muitas pesquisas e inúmeros processos ópticos e químicos foram feitos até chegar a primeira fotografia. " Até então o homem vulgar apenas podia visualizar fenômenos que se passavam por perto dele, na sua rua, na sua aldeia. 


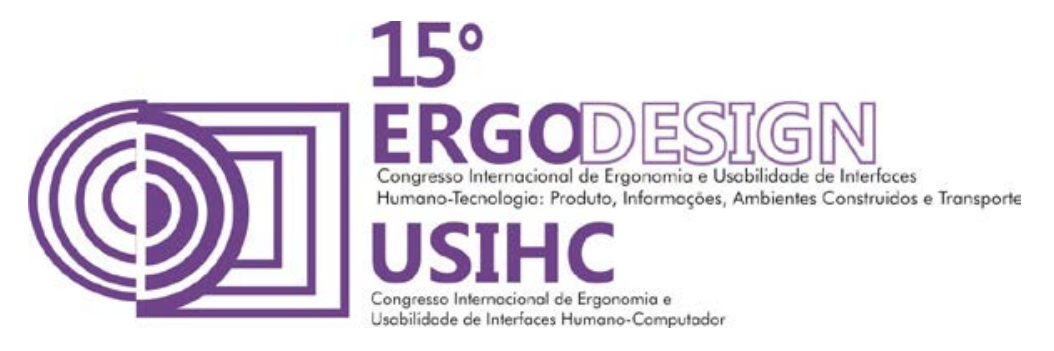

Com a fotografia abre-se uma janela para o mundo" (FREUND, 1995, p.107). Com o passar do tempo houve muitas inovações tecnológicas e os processos fotográficos foram evoluindo tornando a fotografia um meio de propagar e exibir o indivíduo ao público.

Com esse avanço a fotografia ganhou uma linguagem própria, se difundiu e percorreu vários meios de comunicação. A criação de aparelhos celulares com câmera facilitou consideravelmente a interação das pessoas com a fotografia. Tornou-se possível aplicar efeitos, cortar e ampliar as imagens sem a ajuda de um profissional.

Além disso, o crescente uso das redes sociais fez da fotografia um veículo de comunicação com o mundo. Através dela é possível retratar e compartilhar a realidade e seus aspectos subjetivos e objetivos. O sujeito passou a mostrar ao mundo inúmeras facetas construindo assim uma dupla realidade. São comportamentos que indicam um desejo de reconhecimento, atribuição de valores sociais e uma predominante cultura do que é "belo" na atualidade. Esse "encarar a câmara é sinônimo de solenidade, franqueza,revelação da nossa essência" (SONTAG. 1981, p.38).

Inserida no dia a dia das pessoas, tornou-se habitual registrar todo o tipo de momento. Um exemplo o recente é o movimento dos chamados 'selfies' em redes sociais virtuais, um fenômeno de visualização e interação entre pessoas conhecidas ou não. Diante disto destacase a necessidade compreender um pouco mais sobre o fenômeno da relaçãousuários e suas câmeras de celulares: quais recursos são considerados mais importantes, por quê e quais os contextos de uso?

O presente artigo tem por objetivo apresentar o relato de um estudo onde buscou-se compreender a preferência dos usuários pelos serviços instalados junto com o sistema Android, os chamados aplicativos nativos. A partir de observações e entrevistas chegou-se a resultados que sugerem que usuários de smartphones preferem recursos não nativos devido à limitações e ausência de funções de personalização nos aplicativos nativos.

Através da análise de conteúdo proposta por Bardin (2011) foi possível entender que a expectativa em relação a este recurso vai além da funcionalidade de registrar uma cena. A análise proposta tem como ponto focal reunir as ideias ilustradas pelos entrevistados sobre três questões centrais, a saber: interação com a câmera, funcionalidade da câmera e recursos extras.

\section{MATERIAIS E MÉTODOS}

O estudo foi realizado com um total de onze participantes com faixa etária entre 18 a 25 anos. A amostra foi constituída por usuários de smartphones que utilizam a câmera e recursos para edição de imagens. Para garantir diferentes visões de uso, o tempo de experiência do usuário com aplicativos de câmera digital não foi um fator decisivo na seleção dos participantes da pesquisa.

O estudo foi composto de duas etapas: na primeira etapa um levantamento exploratório foi realizado através da análise de serviços disponíveis em um aplicativo nativo e aplicativos nãonativos. A análise norteou a construção de um questionário semi-estruturado composto por 12 perguntas. Na segunda etapa o questionário foi utilizado para estimular a discussão sobre as preferências e o uso de aplicações nativas e não nativas do celular.

Todos os participantes relataram possuir pelo menos uma aplicação não nativa para o recurso de câmera, são eles: Cymera e Fotorus. Entrevistas em profundidade foram realizadas em locais e horários diferenciados como: casa dos entrevistados, faculdade, 


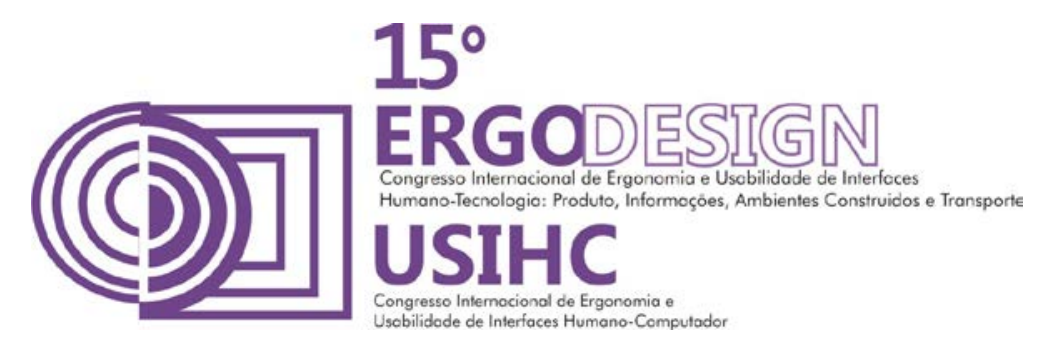

livraria e praça pública. Optou-se pela realização de entrevistas individuais, aplicadas por meio de um roteiro semi-estruturado, gravadas em áudio e transcritas de forma a compor a análise de conteúdo.

"A análise de conteúdo é um conjunto de técnicas de análise das comunicações. Não se trata de um instrumento, mas de um leque de apetrechos; ou, com maior rigor, será um único instrumento, mas marcado por uma grande disparidade de formas e adaptável a um campo de dilatação muito vasto: as comunicações" (BARDIN.2011,p.31).

É importante esclarecer que a mesma é dividida em três fases:

- Pré-análise:é ordenado e estabelecido procedimentos sistemáticos que serão utilizados no contato com os documentos, ou seja, com os dados coletados.

- Exploração do material: são selecionados as unidades de codificação, categorias, subcategorias e reunião das unidades de registros e contexto. "Unidade de contexto é a unidade de significação a codificar. Pode ser o tema, a palavra ou frase. Recorta-se o texto em função da unidade de registro. Tema é a afirmação de um assunto. Como unidade de registro, é a unidade que se liberta naturalmente do texto analisado" (Bardin, 2011).

- Tratamento dos resultados: momento de tornar os resultados válidos e compreender os conceitos que são a base da comunicação, pois nos fornece informações.

Para Bardin (2011) "o analista é como um arqueólogo. Trabalha com vestígios: os documentos que pode descobrir ou suscitar.

Uma vez que o foco da pesquisa é o aplicativo de câmera, não houve preferência pela marca ou modelo de aparelho. A delimitação foi baseada pela categoria Smartphone um aparelho com sistema operacional, que permite desempenhar com eficiência vários recursos simultaneamente. As marcas e modelos de smartphones utilizados nesse estudo foram: Samsung Galaxy S3 NEO, Samsung Win Duos, Iphone 4, Samsung GalaxyGran Duos, Sony Xperia XP, Motorola Moto G, Samsung SIITV, Samsung Pocket, Samsung Ace Duos.

Durante a coleta de dados procurou-se investigar desde as dificuldades e necessidades dos usuários de smartphones até sua satisfação com os recursos da câmera para assim conhecer como é estabelecida essa relação. Um outro objetivo do estudo foi identificar a razão da procura por mais recursos de edição de fotos em outros aplicativos. Por ser um estudo de caráter qualitativo não se buscou coletar dados quantificáveis, mas sim particularidades, experiências individuais que facilitem na identificação dos objetivos da pesquisa.

\section{ANÁLISE DOS DADOS}

Na primeira etapa da pesquisa os dados foram transcritos, analisados e adaptados ao conteúdo e objetivo da pesquisa. Para a análise de dados criou-se categorias e subcategorias a partir das verbalizações dos entrevistados. "As categorias, são rubricas ou classes, as quais reúnem um grupo de elementos...sob um título genérico, agrupamento esse efetuado em razão dos caracteres comuns destes elementos" (BARDIN, 2011). e as sub-categorias referem-se aos aspectos específicos observados em cada categoria principal. Na segunda etapa observou-se as verbalizações e através delas foram extraídas as unidades de registros e unidade de contexto. Este processo de categorização e análise foi aplicado para cada um dos entrevistados (Tabelas 1 a 11). 


\begin{tabular}{|c|c|c|c|}
\hline Categorias & Subcategorias & Unidade de registro E:1 & Unidade de contexto E:1 \\
\hline Interação com a câmera & $\begin{array}{l}\text { - A importância da câmera na escolha do } \\
\text { celular } \\
\text { - } \quad \text { A frequência de uso da câmera nativa } \\
\text { - } \quad \text { Dificuldades de uso da câmera }\end{array}$ & $\begin{array}{l}\text { Câmera nativa } \\
\text { Compartilhamento }\end{array}$ & $\begin{array}{l}\text { - A escolha do celular foi mais pela câmera. } \\
\text { - Uso a câmera em passeios, com os filhos e nos fins de semanas. } \\
\text { - Não tenho dificuldades com a câmera nativa. }\end{array}$ \\
\hline Funcionalidades da câmera & $\begin{array}{ll}\text { - } & \text { Necessidade de uso } \\
\text { - } & \text { Recursos oferecidos } \\
\text { - } & \text { Recursos mais usados } \\
\text { - } & \text { Recursos inexistentes }\end{array}$ & $\begin{array}{l}\text { Flash } \\
\text { lluminação } \\
\text { Escalas } \\
\text { Compartilhar } \\
\text { Modo } \\
\text { Clarear foto }\end{array}$ & $\begin{array}{l}\text { - } \quad \text { Não uso o recurso MODO. } \\
\text { - } \quad \text { Gosto da iluminação para clarear as fotos. } \\
\text { - } \quad \text { Aão uso escalas. } \\
\text { - sociaisera nativa não tem opção de compartilhamento em redes }\end{array}$ \\
\hline Recursos extras & $\begin{array}{l}\text { - } \text { Motivo de usar recursos extras } \\
\text { - } \quad \text { Momentos de uso do novo recurso } \\
\text { - } \\
\text { - } \\
\text { Insacilidades de uso } \\
\text { Insfação }\end{array}$ & Aplicativo Cymera & $\begin{array}{l}\text { - Não acho os efeitos do aplicativo tão atuais. } \\
\text { - } \quad \text { Um amigo meu indicou o aplicativo e baixei. }\end{array}$ \\
\hline
\end{tabular}

Tabela 1. Categorização, sub-categorização, unidade de registro e unidade de contexto para entrevistado 1

\begin{tabular}{|c|c|c|c|}
\hline Categorias & Subcategorias & $\begin{array}{c}\text { Unidade de registro } \\
\text { E:2 }\end{array}$ & Unidade de contexto E:2 \\
\hline Interação com a câmera & $\begin{array}{l}\text { - A importância da câmera na escolha do } \\
\text { celular } \\
\text { - } \quad \text { A frequência de uso da câmera nativa } \\
\text { - } \quad \text { Dificuldades de uso da câmera }\end{array}$ & $\begin{array}{l}\text { Momento da compra do } \\
\text { celular } \\
\text { Câmera frontal }\end{array}$ & $\begin{array}{l}\text { - Não foi prioridade, mas perguntei se a câmera era boa e se tinha } \\
\text { câmera frontal. Gosto de tirar fotos com os amigos. Não tive } \\
\text { dificuldade no uso da câmera. }\end{array}$ \\
\hline Funcionalidades da câmera & $\begin{array}{ll}\text { - } & \text { Necessidade de uso } \\
\text { - } & \text { Recursos oferecidos } \\
\text { - } & \text { Recursos mais usados } \\
\text { - } & \text { Recursos inexistentes }\end{array}$ & $\begin{array}{l}\text { Escalas } \\
\text { Zoom } \\
\text { Câmera nativa }\end{array}$ & $\begin{array}{l}\text { - Gosto do zoom, mas poderia ser melhor, para tirar fotos mais } \\
\text { distantes. } \\
\text { - A câmera nativa só tem } 4 \text { filtros. Não uso escalas. Acho ruim não } \\
\text { ter flash na câmera frontal. }\end{array}$ \\
\hline
\end{tabular}




\begin{tabular}{|l|ll|l|l|}
\hline & $\bullet$ & Motivo de usar recursos extras & $\begin{array}{l}\text { Uso o aplicativo para escrever nas imagens, para por gravuras, } \\
\text { fazer montagens, muitos recursos que a câmera nativa não tem. }\end{array}$ \\
\cline { 2 - 3 } & $-\quad$ Momentos de uso do novo recurso & $\begin{array}{l}\text { Aplicativo fotorus } \\
\text { Montagens } \\
\text { Filtros } \\
\text { Molduras } \\
\text { Vídeos }\end{array}$ & $\begin{array}{l}\text { Uso o filtro em todas as imagens.Corto as fotos, gosto de poder } \\
\text { colocar mais de uma foto na imagem. Insatisfação por não poder } \\
\text { adicionar vídeos nas montagens. }\end{array}$ \\
\hline
\end{tabular}

Tabela 2. Categorização, sub-categorização, unidade de registro e unidade de contexto para entrevistado 2

\begin{tabular}{|c|c|c|c|}
\hline Categorias & Subcategorias & Unidade de registro E:3 & Unidade de contexto E:3 \\
\hline Interação com a câmera & $\begin{array}{l}\text { - A importância da câmera na escolha do } \\
\text { - } \quad \text { A frequêencia de uso da câmera nativa } \\
\text { - } \quad \text { Dificuldades de uso da câmera }\end{array}$ & $\begin{array}{l}\text { Câmera } \\
\text { Print } \\
\text { arquivos word } \\
\text { planilhas } \\
\text { fotos }\end{array}$ & $\begin{array}{l}\text { - A câmera foi importante, as possibilidades de abrir arquivos } \\
\text { no celular. } \\
\text { - A qualidade das fotos são boas, poder tirar foto dos assuntos } \\
\text { na faculdade. } \\
\text { - Não encontrou dificuldades na utilização da câmera. }\end{array}$ \\
\hline Funcionalidades da câmera & $\begin{array}{ll}- & \text { Necessidade de uso } \\
\text { - } & \text { Recursos oferecidos } \\
\text { - } & \text { Recursos mais usados } \\
\text { - } & \text { Recursos inexistentes }\end{array}$ & $\begin{array}{l}\text { Câmera frontal } \\
\text { Câmera nativa } \\
\text { Nitidez } \\
\text { Modo } \\
\text { Temporizador } \\
\text { Recurso de voz }\end{array}$ & $\begin{array}{l}\text { - Gosto da opção de tirar fotos com a câmera frontal em } \\
\text { - } \quad \text { Gosto da opção de tirar vários tipos de imagens e escolher a } \\
\text { - } \quad \text { Gelhor. } \\
\text { - } \quad \text { Tirar o print e fotos são os recursos que mais utilizo. } \\
\text { - } \quad \begin{array}{l}\text { Acho que precisa melhorar algumas coisas como: molduras, } \\
\text { filtros entre outras coisas que não tem na câmera nativa. }\end{array}\end{array}$ \\
\hline Recursos extras & $\begin{array}{l}\text { - } \quad \text { Motivo de usar recursos extras } \\
\text { - } \quad \text { Momentos de uso do novo recurso } \\
\text { - } \quad \text { Insatidades de uso } \\
\text { ano }\end{array}$ & $\begin{array}{l}\text { Aplicativo cymera } \\
\text { Aplicativo fotorus } \\
\text { Filtros } \\
\text { Molduras } \\
\text { Postar fotos }\end{array}$ & $\begin{array}{l}\text { - } \quad \text { Baixei o aplicativo devido ter molduras,filtros, coisas que a } \\
\text { câmera nativa não tem. } \\
\text { - Gosto de postar as fotos sem precisar cortar. Utilizo o } \\
\text { aplicativo em quase todas as fotos. } \\
\text { - Não tive dificuldade e o que não sabia as outras pessoas } \\
\text { falavam. } \\
\text { - } \quad \text { Gostaria de ter na câmera frontal um flash e que } \\
\text { melhorassem o zoom para a foto não ficar embaçada. }\end{array}$ \\
\hline
\end{tabular}

Tabela 3. Categorização, sub-categorização, unidade de registro e unidade de contexto para entrevistado 3 


\begin{tabular}{|c|c|c|c|}
\hline Categorias & Subcategorias & Unidade de registro E:4 & Unidade de contexto E:4 \\
\hline Interação com a câmera & $\begin{array}{l}\text { - A importância da câmera na escolha do } \\
\text { celular } \\
\text { - } \quad \text { A frequência de uso da câmera nativa } \\
\text { Dificuldades de uso da câmera }\end{array}$ & $\begin{array}{l}\text { Câmera nativa } \\
\text { Operações básicas } \\
\text { Zoom }\end{array}$ & $\begin{array}{l}\text { - } \quad \text { O celular era da minha mãe. } \\
\text { - Não utilizo muito a câmera nativa devido não tirar muitas } \\
\text { - } \quad \text { Notos. } \\
\text { bão tem muitas funções a câmera e são só as operações } \\
\text { - O zoom não pega em vídeos. }\end{array}$ \\
\hline Funcionalidades da câmera & $\begin{array}{ll}\text { - } & \text { Necessidade de uso } \\
\text { - } & \text { Recursos oferecidos } \\
\text { - } & \text { Recursos mais usados } \\
& \text { Recursos inexistentes }\end{array}$ & $\begin{array}{l}\text { Câmera } \\
\text { Modo } \\
\text { vídeos } \\
\text { compartilhamento }\end{array}$ & $\begin{array}{l}\text { - } \quad \text { Para editar mesmo não tem recursos bons. } \\
\text { no celular eu posso tirar fotos e postar nas redes sociais }\end{array}$ \\
\hline Recursos extras & $\begin{array}{ll}\text { - } & \text { Motivo de usar recursos extras } \\
\text { - } & \text { Momentos de uso do novo recurso } \\
\text { - } & \text { Insatisfades de uso } \\
& \text { Inso }\end{array}$ & $\begin{array}{l}\text { Aplicativo FotoRus } \\
\text { compartilhamento em } \\
\text { redes sociais } \\
\text { PIP filtros }\end{array}$ & $\begin{array}{l}\text { - } \quad \text { Fiquei sabendo do aplicativo através de amigos que usavam } \\
\text { - } \quad \text { Posso postar no Instagram sem precisar cortar a foto. } \\
\text { imagem ex: dentro do copo, dentro do gelo. } \\
\text { - Não gosto no momento da edição da foto não poder retirar } \\
\text { apenas um efeito que não gostei e tenho que fazer tudo } \\
\text { novamente. }\end{array}$ \\
\hline
\end{tabular}

Tabela 4. Categorização, sub-categorização, unidade de registro e unidade de contexto para entrevistado4

\begin{tabular}{|c|c|c|c|}
\hline Categorias & Subcategorias & Unidade de registro E:5 & Unidade de contexto E:5 \\
\hline Interação com a câmera & $\begin{array}{l}\text { - A importância da câmera na escolha do } \\
\text { celular } \\
\text { - } \quad \text { A frequência de uso da câmera nativa } \\
\text { Dificuldades de uso da câmera }\end{array}$ & $\begin{array}{l}\text { Câmera } \\
\text { Qualidade da imagem } \\
\text { Recursos da câmera }\end{array}$ & $\begin{array}{l}\text { - } \quad \text { Eu já sabia que a qualidade da imagem seria boa. } \\
\text { - } \quad \text { s recursos da câmera são ótimos, mas não uso muito } \\
\text { devido a qualidade da imagem ser boa. } \\
\text { - } \quad \text { Uso a câmera todos os dias. } \\
\text { - } \quad \text { nãtidez da imagem é o que tem de melhor. } \\
\text { - } \quad \text { ãve dificuldade em usar os recursos. }\end{array}$ \\
\hline Funcionalidades da câmera & $\begin{array}{ll}\text { - } & \text { Necessidade de uso } \\
\text { - } & \text { Recursos oferecidos } \\
\text { - } & \text { Recursos mais usados } \\
\text { - } & \text { Recursos inexistentes }\end{array}$ & $\begin{array}{l}\text { Câmera } \\
\text { nativa/compartilhamento } \\
\text { em redes sociais. }\end{array}$ & $\begin{array}{l}\text { - Eu posso compartilhar direto da câmera nativa para as redes } \\
\text { sociais. } \\
\text { - Tem bons recursos a câmera. }\end{array}$ \\
\hline
\end{tabular}




\begin{tabular}{|c|c|c|c|}
\hline Recursos extras & $\begin{array}{l}\text { - Motivo de usar recursos extras } \\
\text { - } \text { Momentos de uso do novo recurso } \\
\text { - } \\
\text { - } \\
\text { - Insacilidades de uso } \\
\end{array}$ & $\begin{array}{l}\text { Aplicativo Fotorus } \\
\text { Instasize } \\
\text { Molduras } \\
\text { Câmera } \\
\text { Foto }\end{array}$ & $\begin{array}{l}\text { - Baixei para ver como iria ser na hora de editar a foto e gosto } \\
\text { de molduras diferentes. Uso para postar fotos no instagram } \\
\text { sem precisar cortar a foto, mas não gosto dos efeitos que } \\
\text { não deixam a foto natural. } \\
\text { - } \quad \text { Não gosto de editar muito as fotos. } \\
\text { - } \quad \text { Gosto do InstaSize por ser um aplicativo do instagram. } \\
\text { - Não mudaria nada nesse aplicativo e se eu não quiser mais } \\
\text { é só desinstalar. }\end{array}$ \\
\hline
\end{tabular}

Tabela 5. Categorização, sub-categorização, unidade de registro e unidade de contexto para entrevistado 5

\begin{tabular}{|c|c|c|c|}
\hline Categorias & Subcategorias & Unidade de registro E:6 & Unidade de contexto E: 6 \\
\hline Interação com a câmera & $\begin{array}{l}\text { - A importância da câmera na escolha do } \\
\text { celular } \\
\text { - } \quad \text { A frequência de uso da câmera nativa } \\
\text { - Dificuldades de uso da câmera }\end{array}$ & $\begin{array}{l}\text { Câmera } \\
\text { Flash } \\
\text { Qualidade da imagem }\end{array}$ & $\begin{array}{l}\text { - No momento da compra do celular eu não pensei muito na } \\
\text { - } \quad \text { Eûmera. } \\
\text { - } \quad \text { Uso o flash para tirar fotos a noite. } \\
\text { - } \quad \text { Gosto da qualidade da imagem. } \\
\text { - Não mexo muito em configurações. } \\
\text { - Não tenho dificuldades, uso na escola e com os amigos. }\end{array}$ \\
\hline Funcionalidades da câmera & $\begin{array}{ll}\text { - } & \text { Necessidade de uso } \\
\text { - } & \text { Recursos oferecidos } \\
\text { - } & \text { Recursos mais usados } \\
& \text { Recursos inexistentes }\end{array}$ & $\begin{array}{l}\text { Foco } \\
\text { Modo automático } \\
\text { Configurações } \\
\text { Som da câmera } \\
\text { Escalas }\end{array}$ & $\begin{array}{l}\text { - Uso enquadramento para tirar fotos distantes e quando } \\
\text { - } \quad \text { Fuero que fique centralizado. } \\
\text { automático. } \\
\text { - Uso os sons da câmera apenas para saber quando a foto foi } \\
\text { - } \quad \text { capturada se estou tirando foto de mim. } \\
\text { - Não tem flash na câmera frontal e isso deixa a foto escura. }\end{array}$ \\
\hline Recursos extras & $\begin{array}{ll}\text { - } & \text { Motivo de usar recursos extras } \\
\text { - } & \text { Momentos de uso do novo recurso } \\
\text { - } & \text { Insatidades de uso } \\
& \text { Inão }\end{array}$ & $\begin{array}{l}\text { Câmera } \\
\text { Filtros } \\
\text { bordas } \\
\text { efeitos } \\
\text { aplicativo cymera } \\
\text { colagens }\end{array}$ & $\begin{array}{l}\text { - Uso o cymera para melhorar as fotos, colocar filtros, fazer } \\
\text { colagens e tirar defeitos. } \\
\text { - Uso sempre para editar as fotos que escolho para postar. } \\
\text { - Uso com frequência é com um passa-tempo ficar editando } \\
\text { fotos. } \\
\text { - } \quad \text { Oosso colocar bordas, borrar a foto. } \\
\quad \text { câmera tive ajuda muito a melhorar a foto. Gostaria que a } \\
\text { baixar um aplicativo. }\end{array}$ \\
\hline
\end{tabular}

Tabela 6. Categorização, sub-categorização, unidade de registro e unidade de contexto para entrevistado 6 


\begin{tabular}{|c|c|c|c|}
\hline Categorias & Subcategorias & Unidade de registro E:7 & Unidade de contexto E:7 \\
\hline Interação com a câmera & $\begin{array}{l}\text { - A importância da câmera na escolha do celular } \\
\text { - } \quad \text { frequência de uso da câmera nativa } \\
\quad \text { Dificuldades de uso da câmera }\end{array}$ & $\begin{array}{l}\text { Câmera } \\
\text { Câmera frontal } \\
\text { Qualidade de imagem } \\
\text { Configurações }\end{array}$ & $\begin{array}{l}\text { - No momento que fui comprar o celular o que me chamou } \\
\text { - } \quad \text { atenção foi o design do celular e as funções da câmera. } \\
\text { funções que eu queria para melhorar a foto. } \\
\text { - } \quad \text { Gosto da câmera frontal mas a qualidade não é boa. } \\
\text { - O que atrapalha para tirar fotos é o formato do celular } \\
\text { - } \quad \text { dependendo do ângulo. } \\
\text { - Não as configurações apenas por curiosidade. } \\
\quad \text { Não dificuldade para usar a câmera nativa. }\end{array}$ \\
\hline Funcionalidades da câmera & $\begin{array}{ll}\text { - } & \text { Necessidade de uso } \\
\text { - } & \text { Recursos oferecidos } \\
\text { - } & \text { Recursos mais usados } \\
\text { - } & \text { Recursos inexistentes }\end{array}$ & $\begin{array}{l}\text { Modo automático } \\
\text { Câmera frontal } \\
\text { Escalas } \\
\text { Compartilhamento }\end{array}$ & $\begin{array}{l}\text { - } \quad \text { câmera frontal não deixa a imagem muito nítida. } \\
\text { - Uso apenas o modo automático ele avisa quando tem pouca } \\
\text { - } \quad \text { Tem escalas mas não uso. } \\
\text { - A câmera não compartilha, tiro foto elas vão para a galeria e } \\
\text { de lá que tem a opção de compartilhamento. }\end{array}$ \\
\hline Recursos extras & $\begin{array}{ll}\text { - } & \text { Motivo de usar recursos extras } \\
\text { - } & \text { Momentos de uso do novo recurso } \\
\text { - } & \text { Insatidades de uso } \\
& \text { Ino }\end{array}$ & $\begin{array}{l}\text { Aplicativo Cymera } \\
\text { clareamento de fotos } \\
\text { filtros. }\end{array}$ & $\begin{array}{l}\text { - Uso o cymera para editar as fotos, tiro a foto na câmera } \\
\text { nativa e depois edito no aplicativo para tirar imperfeições e } \\
\text { clarear as fotos. } \\
\text { - } \quad \text { Quase todas as fotos passam pelo editor. } \\
\text { - Uso os filtros do aplicativo que são melhores do que os que } \\
\text { vem na câmera do celular. } \\
\text { - Tem funções desnecessárias no aplicativo como aplicar } \\
\text { cabelo e não fica bom. }\end{array}$ \\
\hline
\end{tabular}

Tabela 7. Categorização, sub-categorização, unidade de registro e unidade de contexto para entrevistado 7

\begin{tabular}{|c|c|c|c|}
\hline Categorias & Subcategorias & Unidade de registro E:8 & Unidade de contexto E:8 \\
\hline Interação com a câmera & $\begin{array}{l}\text { - A importância da câmera na escolha do celular } \\
\text { - } \quad \text { A frequência de uso da câmera nativa } \\
\text { - Dificuldades de uso da câmera }\end{array}$ & $\begin{array}{l}\text { Câmera } \\
\text { Qualidade da imagem }\end{array}$ & $\begin{array}{l}\text { - O que chamou atenção foi a marca do celular e depois } \\
\text { percebi que a câmera era boa. } \\
\text { - A qualidade da imagem é boa, mas não sou mito de editar } \\
\text { fotos. } \\
\text { - Uso o flash raramente quando o ambiente tem pouca luz. }\end{array}$ \\
\hline Funcionalidades da câmera & $\begin{array}{ll} & \text { Necessidade de uso } \\
\text { - } & \text { Recursos oferecidos } \\
\text { - } & \text { Recursos mais usados } \\
& \text { Recursos inexistentes }\end{array}$ & $\begin{array}{l}\text { Câmera } \\
\text { resolução de imagem } \\
\text { configurações } \\
\text { modo automático }\end{array}$ & $\begin{array}{l}\text { - A resolução é boa. Sempre fica no modo automático. } \\
\text { - Não tenho o hábito de ficar mexendo nas configurações } \\
\text { - Não sei o que eu gostaria que a câmera tivesse }\end{array}$ \\
\hline
\end{tabular}




\begin{tabular}{|c|c|c|c|}
\hline Recursos extras & $\begin{array}{ll}\text { - } & \text { Motivo de usar recursos extras } \\
\text { - } & \text { Momentos de uso do novo recurso } \\
\text { - } \quad \text { Insatisfades de usa a }\end{array}$ & Aplicativo fotorus & $\begin{array}{l}\text { - Uso o aplicativo fotorus apenas para postar fotos no tamanho } \\
\text { real. Amigos indicaram e eu baixei. } \\
\text { - } \quad \text { Me ajuda na hora de postar e fica bom. } \\
\quad \text { Ruim é quando o aplicativo trava. }\end{array}$ \\
\hline
\end{tabular}

Tabela 8. Categorização, sub-categorização, unidade de registro e unidade de contexto para entrevistado 8

\begin{tabular}{|c|c|c|c|}
\hline CATEGORIAS & SUBCATEGORIAS & Unidade de registro E:9 & Unidade de contexto E:9 \\
\hline Interação com a câmera & $\begin{array}{l}\text { - A importância da câmera na escolha do celular } \\
\text { - } \quad \text { A frequência de uso da câmera nativa } \\
\text { - Dificuldades de uso da câmera }\end{array}$ & $\begin{array}{l}\text { Câmera } \\
\text { Aparência do aplicativo } \\
\text { Ferramentas da câmera }\end{array}$ & $\begin{array}{l}\text { - O importante era ter um celular android. A câmera só fez } \\
\text { uma diferença a mais se não tivesse câmera certamente eu } \\
\text { não compraria o celular. } \\
\text { - A aparência não me agrada muito, seria bom se tivesse um } \\
\text { tema mais bonito, ícones mais agradáveis de se ver. } \\
\text { - Deveria ter um botão na lateral para facilitar na hora de tirar } \\
\text { fotos. } \\
\text { - Gostaria que a câmera tivesse todos os recursos de uma } \\
\text { programa fotoshop. }\end{array}$ \\
\hline Funcionalidades da câmera & $\begin{array}{ll}- & \text { Necessidade de uso } \\
\text { - } & \text { Recursos oferecidos } \\
\text { - } & \text { Recursos mais usados } \\
& \text { Recursos inexistentes }\end{array}$ & $\begin{array}{l}\text { Recursos da câmera } \\
\text { Câmera frontal Qualidade } \\
\text { da imagem. }\end{array}$ & $\begin{array}{l}\text { A câmera é um recurso que uso sempre em todos os } \\
\text { lugares, na faculdade, em casa, com amigos, família, tiro foto } \\
\text { de tudo. } \\
\text { - A câmera frontal não tem flash e contra a luz a imagem fica } \\
\text { ruim. } \\
\text { - Os outros recursos eu utilizo dependendo da foto a ser } \\
\text { tirada. } \\
\text { A qualidade poderia ser melhor, mas posso melhorar a } \\
\text { imagem usando outros aplicativos. }\end{array}$ \\
\hline Recursos extras & $\begin{array}{ll}\text { - } & \text { Motivo de usar recursos extras } \\
\text { - } \quad \text { Momentos de uso do novo recurso } \\
\text { - } \quad \text { Insatisfação }\end{array}$ & $\begin{array}{l}\text { Aplicativo cymera } \\
\text { Aplicativo fotorus } \\
\text { Postagem de fotos } \\
\text { Recursos do aplicativo }\end{array}$ & $\begin{array}{l}\text { - Uso o cymera e fotorus não tem como postar uma foto sem } \\
\text { - } \quad \text { Semprar. } \\
\text { foto. } \\
\text { - Gosto de postar as fotos sem precisar cortar as imagens e } \\
\text { com o fotorus eu posto no tamanho normal.As molduras são } \\
\text { bem criativas. } \\
\text { - Não gosto quando trava e demora a carregar a edição. } \\
\text { - É chato quando essesaplicativos pedem atualizações. }\end{array}$ \\
\hline
\end{tabular}

Tabela 9. Categorização, sub-categorização, unidade de registro e unidade de contexto para entrevistado 9

\begin{tabular}{|c|c|c|c|}
\hline Categorias & Subcategorias & $\begin{array}{c}\text { Unidade de registro } \\
\text { E:10 }\end{array}$ & Unidade de contexto E:10 \\
\hline
\end{tabular}




\begin{tabular}{|c|c|c|c|}
\hline Interação com a câmera & $\begin{array}{l}\text { - } \quad \text { importância da câmera na escolha do celular } \\
\text { - } \quad \text { Dificulequadades de uso da câmera nativa } \\
\end{array}$ & $\begin{array}{l}\text { Câmera } \\
\text { Qualidade de imagem }\end{array}$ & $\begin{array}{l}\text { - O celular é pequeno e a qualidade das imagens não são } \\
\text { boas. } \\
\text { - Tem as funções básicas, tem flash, prefiro tirar foto na } \\
\text { - } \quad \text { Não vejo nada de diferente no visual, é fácil de usar. }\end{array}$ \\
\hline Funcionalidades da câmera & $\begin{array}{ll}\text { - } & \text { Necessidade de uso } \\
\text { - } & \text { Recursos oferecidos } \\
\text { - } & \text { Recursos mais usados } \\
& \text { Recursosistentes }\end{array}$ & $\begin{array}{l}\text { Modo automático } \\
\text { Redes sociais } \\
\text { Escalas } \\
\text { Compartilhamento. }\end{array}$ & $\begin{array}{l}\text { - Uso mais o modo automático, já usei o modo noturno, mas } \\
\text { não vi diferenças depois. } \\
\text { Não utilizo escalas, não uso muito o celular para postar fotos } \\
\text { nas redes sociais. }\end{array}$ \\
\hline Recursos extras & $\begin{array}{ll}\text { - } & \text { Motivo de usar recursos extras } \\
\text { - } & \text { Momentos de uso do novo recurso } \\
\text { - } \quad \text { Insatidades de uso } & \text { Insação }\end{array}$ & Aplicativo Cymera & $\begin{array}{l}\text { - Tenho o aplicativo porque foi indicação de outras pessoas e } \\
\text { - } \quad \text { Nunci legal ter um aplicativo para editar fotos as vezes. } \\
\text { - } \quad \text { ão uso muito o aplicativo e não pensei se tinha algo que eu } \\
\text { gostaria de mudar }\end{array}$ \\
\hline
\end{tabular}

Tabela 10. Categorização, sub-categorização, unidade de registro e unidade de contexto para entrevistado10

\begin{tabular}{|c|c|c|c|}
\hline Categorias & Subcategorias & $\begin{array}{c}\text { Unidade de registro } \\
\text { E:11 }\end{array}$ & Unidade de contexto E:11 \\
\hline Interação com a câmera & $\begin{array}{l}\text { - A importância da câmera na escolha do celular } \\
\text { - } \quad \text { A frequência de uso da câmera nativa } \\
\text { Dificuldades de uso da câmera }\end{array}$ & Câmera & $\begin{array}{l}\text { - A câmera é boa. } \\
\text { - Uso muito a câmera para tirar fotos do móveis que meu } \\
\text { marido faz. } \\
\text { - A câmera é simples não tenho dificuldades. }\end{array}$ \\
\hline Funcionalidades da câmera & $\begin{array}{ll}- & \text { Necessidade de uso } \\
- & \text { Recursos oferecidos } \\
\text { - } & \text { Recursos mais usados } \\
& \text { Recursos inexistentes }\end{array}$ & $\begin{array}{l}\text { Câmera } \\
\text { Galeria de fotos } \\
\text { Modos Compartilhamento }\end{array}$ & $\begin{array}{l}\text { - A câmera deve ter esses recursos de foco, enquadramento e } \\
\text { - } \quad \text { Essa opção de tirar foto tocando na tela é ruim as vezes a } \\
\text { foto fica tremida. } \\
\text { - Gosto como ficam armazenadas na galeria as fotos. } \\
\text { - Sempre uso o modo automático. } \\
\text { - } \quad \text { Aso disparo contínuo para não precisar tocar na tela. } \\
\text { diretamente, sempre vou pelo aplicativo. }\end{array}$ \\
\hline Recursos extras & $\begin{array}{ll}\text { - } & \text { Motivo de usar recursos extras } \\
\text { - } & \text { Momentos de uso do novo recurso } \\
\text { - } \quad \text { Insatidades de uso } \\
\quad \text { Insãa }\end{array}$ & $\begin{array}{l}\text { Aplicativo Cymera Efeitos } \\
\text { dos aplicativos }\end{array}$ & $\begin{array}{l}\text { - } \quad \text { O aplicativo cymera foi minha filha quem baixou. } \\
\text { - } \quad \text { Gostei dos efeitos do aplicativo, molduras e filtros. } \\
\text { - } \quad \text { Mas sempre tem uns problemas de travar o aplicativo, } \\
\text { demora para ver a imagem, não são os melhores recursos. }\end{array}$ \\
\hline
\end{tabular}

Tabela 11. Categorização, sub-categorização, unidade de registro e unidade de contexto para entrevistado 11 


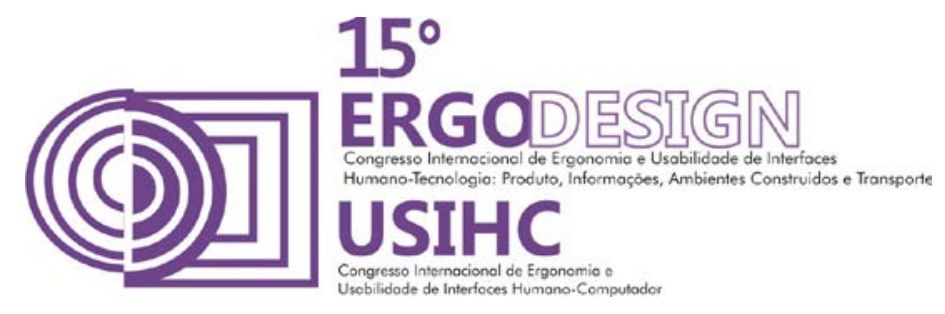

\section{RESULTADOS}

Após a transcrição dos dados foi possível identificar os motivos que levaram os respondentes a buscar recursos não nativos para a câmera do aparelho celular. A busca por novos recursos dáse pela ausência de ferramentas no aplicativo nativo, tais como: recurso para compartilhamento direto em redes sociais, poucas opções de filtros, opção para molduras, edição de várias fotos para aplicar um efeito de colagem, ferramentas para correção de imperfeições faciais, flash na câmera frontal. $\mathrm{Na}$ ausência desses recursos os clientes buscam outros editores de imagem para assim melhorar a aparência das suas fotos.

A ausência de flash na câmera frontal para facilitar o registro e qualidade das famosas selfies noturnas também foi destacado pelos participantes. Alguns recursos da câmera não apresentam fácil compreensão. Ex. ISO AUTO, Valor da Exposição.

No que diz respeito a fotos com baixa luminosidade, de acordo com os entrevistados a maioria dos aparelhos e aplicativos testados deixa a desejar. Sobre os recursos disponíveis em aplicativos não nativos destacam-se seguintes recursos:

1) FotoRus: permite usar fotos para criar diversas montagens. Oferece editor de imagens com mais de 50 filtros e 60 molduras. Possibilidade de inserir textos, cor, filtros e compartilhamento em redes sociais.

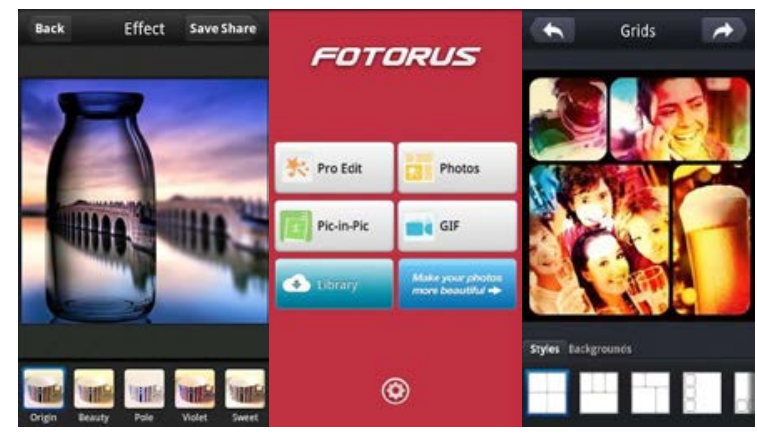

Figura 1 - Tela de personalização de imagens Fotorus

Fonte:www.baixaki.com.br/android/download/fotorus.htm

2) Cymera: possui editor de imagem, reúne diversas ferramentas de edição como: filtros, molduras, efeitos que recriam 7 tipos de lentes das câmeras DSRL, efeitos de embelezamento, adesivos, mascaras e compartilhamento em redes sociais.

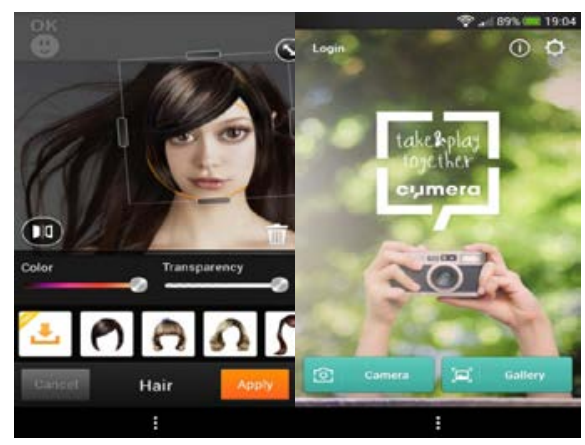

Tela de personalização de imagens Cymera

Fonte: http://app4smart.com/pt/1439-cymera.html 


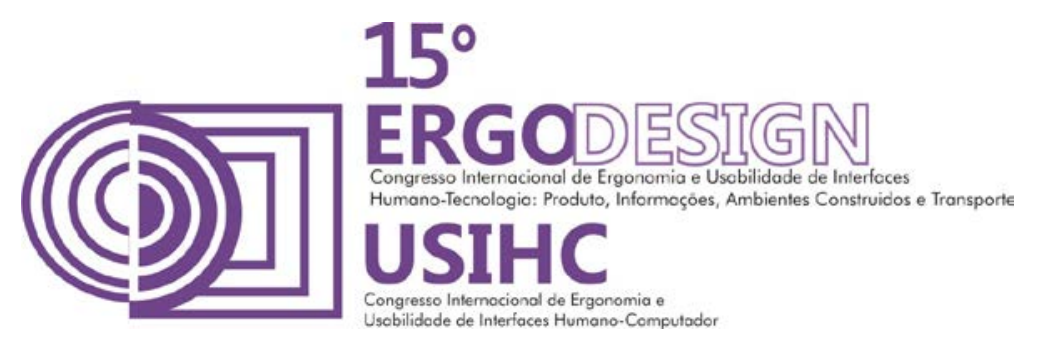

\section{CONSIDERAÇÕES FINAIS}

Ao final desta pesquisa foi possível perceber que o aplicativo de câmera é importante nos smartphones, o seu uso é feito em casa, na faculdade, em passeios com a família entre outros lugares. Segundo um estudo da Hibou, empresa de pesquisa de monitoramento e mercado $58 \%$ tiram fotos ou gravam vídeos e $84 \%$ dos entrevistados disseram que usam seus celulares para compartilhar fotos e ideias em redes sociais (MELLO,2014). Tirar uma fotografia tornou-se um novo recurso de comunicação. Só em 2013 estima-se que foram 109,5 bilhões de registros em apenas uma rede social, o Facebook (Machado, 2013).

Sabe-se que a fotografia "pode ser reduzida, ampliada, cortada, retocada,consertada e distorcida" (SONTAG, 1981, p. 4). A boa aparência influencia as pessoas a buscarem novos recursos como editores de fotos para modificar a imagem colocando-os de acordo com suas preferências. Foi possível observar anecessidade de mais recursos de edição como maior número de filtros, efeitos e ferramentas de embelezamento.

A utilização da análise do conteúdo possibilitou a interpretação dos dados e compreensão da importância de explorar cada item abordado na pesquisa para ter melhores resultados, mesmo que o experimento tenha limitações como tempo e número reduzido de participantes. Isto sugere que somada à outras técnicas este modelo pode complementar os estudos subjetivos relacionados ao uso de produtos.

Observando que a tecnologia influencia no comportamento das pessoas é interessante citar a importância câmera como ferramenta social, pois na tentativa de se adequar as novas tecnologias usuários criam novas opiniões e novas maneiras de agir para se inserir num grupo ou meio social. A partir do estudo surgiram novos cenários que podem ser explorados em outras pesquisas como: privacidade no compartilhamento de imagens e compreensão dos ícones no menu de configuração da câmera.

\section{REFERÊNCIAS BIBLIOGRÁFICAS}

ABDULLA,T.; BLYUDOV, S,; POPA, V.; SUVOROSA, D. Cymera. Portal App4Smart, seção Revisão. Disponível em: < http://app4smart.com/pt/1439-cymera.html> Acesso em 23 de janeiro de 2015 às $17 \mathrm{~h}$.

BARDIN, L.(2011). Análise de conteúdo. São Paulo: Edições 70, Martins Fontes, 2011

BERG, B.L. Qualitative Research Methods for the Social Sciences. University of Michigan: (4th ed.) Allyn and Bacon, 2001.

CALAÇA, Mariana Capeletti. Daguerreotipia: Processo histórico na contemporaneidade. 2012. Apresentação de trabalho. (Graduação). Universidade Federal de Goiás (UFG), Goiânia, 2012.

FREUND, Gisèle. Fotografia e sociedade. Lisboa: Vega, 1995.

MACHADO, A. Porano, 125 bilhões de imagenssãocompartilhadasnarede. Portal $O$ Globo, seçãoTecnologia. Disponívelem: < http://oglobo.globo.com/sociedade/tecnologia/por-ano-125bilhoes-de-imagens-sao-compartilhadas-na-rede-8301345>Acessoem 24 de janeiro de 2015 às $23 \mathrm{~h}$. 


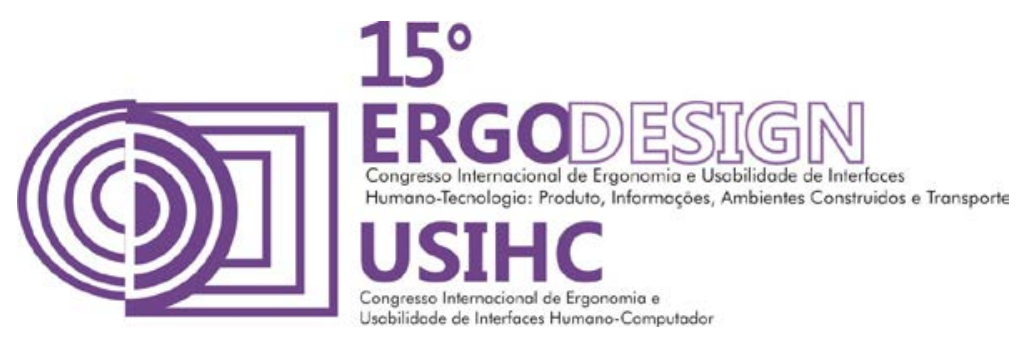

MELLO, L. Pesquisa aponta: $52 \%$ dos paulistanos preferem esquecer as calças do que seus smartphones. Portal R7, Seção Notícias. Disponível em: <http://saopaulotimes.com.br/sp/pesquisaaponta52-dos-paulistanos-preferem-esquecer-as-calcas-do-que-seus-smartephones/> Acesso em 26 de janeiro de 2015 às $9 \mathrm{~h}$.

MULLER, L. Use dezenas de ferramentas para editar, aplicar efeitos e compartilhar suas fotos preferidas nas redes sociais. Portal Baixaki seção Android. Disponível em: $<$ http://www.baixaki.com.br/android/download/fotorus.htm> Acesso em 23 de janeiro de 2015 às 17h.

SONTAG, Susan. Ensaios sobre a Fotografia. Rio de Janeiro: Ed. Arbor, 1981. 